\title{
Structural, thermal and optical studies of bismuth doped multicomponent tellurite glass
}

\begin{abstract}
In this communication, structural, thermal and optical absorption properties of bismuth doped multicomponent tellurite glass $(69 \mathrm{TeO}<\mathrm{sub}>2</ \mathrm{sub}>-10 \mathrm{ZnO}-10 \mathrm{WO}<\mathrm{sub}>3</ \mathrm{sub}>-$ $5 \mathrm{Na}<$ sub $>2</$ sub $>\mathrm{O}-5 \mathrm{TiO}<$ sub $>2</$ sub $>-1.0 \mathrm{Bi}<$ sub $>2</$ sub $>\mathrm{O}<$ sub $>3</$ sub $>\quad($ mol $\%)$ ) synthesized using melt quench method is reported. The X-ray diffraction confirms the amorphous structure of the synthesized glass. IR spectrum of bismuth doped glass show band at $601 \mathrm{~cm}<$ sup $>-1</$ sup $>$. Raman analysis observed mainly in four spectral regions which are R1 (65-150) cm<sup >-1</sup>, R2 (280-550) cm<sup>-1</sup>, R3 (880-950) cm<sup >$1</$ sup $>$ and R4 (916-926) $\mathrm{cm}<$ sup $>-1</$ sup $>$ and identified bands are assigned to respective molecular groups. Thermogravimetric analysis profile show stability regarding to weight loss. Differential scanning calorimetry indicates good thermal stability of the synthesized glass for its applications in optical fibers. The absorption spectrum identified the cutoff wavelength at $430 \mathrm{~nm}$.
\end{abstract}

Keyword: $\quad$ FTIR; RAMAN; Tellurite glass; TGA/DSC; X-Ray diffraction (XRD) 
